\title{
Towards an integral accessible public area in the city
}

\author{
E. De Winne \\ Faculty of Engineering, Department of Civil Techniques, Ghent \\ University, Belgium \\ Road and Traffic Administration, Ministry of the Flemish Community, \\ Belgium
}

\begin{abstract}
It must be possible for everybody to participate in mobility. One condition is that accessibility must be easy enough not only for vehicles but also for children, pedestrians, cyclists, disabled people, blind people or persons with a restricted visibility, and people moving in wheelchairs. Road managers must pay attention to all the movable restrictions.

To be able to assure an integral and safe accessible public area, many measures are necessary, e.g. comfortable pedestrian paths without obstacles, safe crossing points for pedestrians and cyclists, accessible public transport facilities, etc.

A practical guide for those who are interested in safety and comfort in all (restricted) road users is necessary to guarantee a better quality of life.

This paper describes:

- why integral accessibility is an essential condition for mobility management and how to assure reachability for everyone;

- how to elaborate design criteria for an integral accessible public area, related to traffic safety, a freely movable area, a flat and rough surface, with not too many differences in levels, orientations and other measures for blind people or people with restricted visibility, information and service initiatives and measures;

- patterns of pedestrians, links between pedestrians and car drivers or car passengers, links between pedestrians and public transport users, etc;

- conclusions: suggestions for road design, management and maintenance illustrated by some practical and realized cases.

Keywords: public area, traffic safety, reach ability, integral accessibility, public transport.
\end{abstract}




\section{Introduction}

Participation in mobility must be available to everyone. Some years ago, the Flemish government took a legal initiative in order to guarantee an obstacle free area for pedestrians. However, more measures are necessary to obtain obstacle free pedestrian paths, safe crossing points and a better accessible public transport system.

\section{Integral accessibility: an essential link for mobility management}

Several reasons for inaccessibility could be, e.g.,

- a wheelchair obstructed by a drains or parked car

- an unmovable pedestrian path

- privatisation of public areas

- obstacles by building works in progress which are unsafe

- insufficient gaps between street furniture

- slopes and uneven paths

- blocked pavements and drains in bad condition

- traffic lights which are not recognizable by blind people and people with restricted visibility.

These examples show why an integral accessible public area is necessary to guarantee mobility for everybody so they can reach a destination independently under the same and similar conditions for all groups of road users.

\section{Recommended design criteria for an integral accessible area}

\subsection{Traffic safety as reference}

Increasing road safety requires paying consideration to all the sub-systems, people, road and vehicles, which cannot be analyzed separately but through their interactions. In order to understand how elements of road infrastructure should best be placed, it is important to combine an understanding of the interactions between the sub-systems with an understanding of the driver's behaviour. Measures in road engineering in different situations can contribute to the improvement of road safety:

- geometric and design of road infrastructure e.g. increased safety resulting from spatial road alignment

- road equipment including electronic traffic guidance

- pavements and safety e.g. special pavements.

The road aspect and the integration of measures are defined mainly by the allowed speed limits:

- zone 30 areas: more moveability for pedestrians and cyclists

- zone 50 areas: special measures must be taken in order to assure the safety on pedestrian crossing points (zebra) 
- zone 70 areas: traffic lights are recommended for pedestrian crossing points combined with special measures included walking paths for blind people and people with restricted visibility.

\subsection{Free movable pedestrian space}

- the free passage width (normal user intensity) has a minimum of $150 \mathrm{~cm}$ (fig. 1)

- the free space to be able to turn around for wheelchairs users is $150 \mathrm{~cm}$ (fig. 2)

- the free passage height has a minimum of $210 \mathrm{~cm}$

- if the pedestrian area is larger than 2,00 meter, an obstacle free area of 1,50 m wide must always be guaranteed

- if the pedestrian area is between 1,50 and 2,00 m wide, an area of 0,50 meter can be used for obstacles

- pedestrian areas less than 1,50 meter wide can only be constructed on roads with a building line less than 9,00 meter

- pedestrian paths have always an obstacle free runway of 1,00 meter wide and a free height of 2,10 meter.

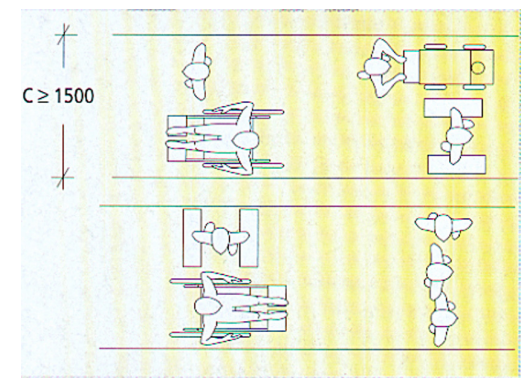

Figure 1.

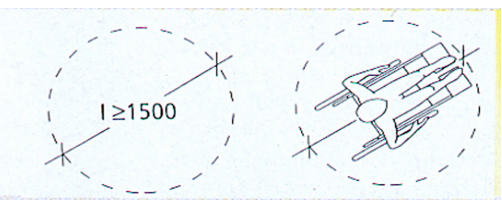

Figure 2 .

\subsection{Evenness and roughness requirements}

- the walking surface area must be obstacle free and flat

- there are conditions to satisfy concerning the choice of the materials and the method of execution

- rough and/or flat means little unevenness $<5 \mathrm{~mm}$

- the transversal slope must be less than 1:50 meter

- the mesh of grills must be less than $2 \mathrm{~cm}$ so that wheelchairs and baby carriages and buggies are allowed to cross over.

\subsection{Differences in levels (Fig. 3)}

- differences in levels have a maximum of $2 \mathrm{~cm}$ for wheelchair users at crossing points 
- differences in levels of more than $2 \mathrm{~cm}$ can be executed with a slope less than $1: 25$

- differences in levels of more than 1,00 meter, can be executed with a slope of more than 1:25, but an additional horizontal rest area is necessary

- the optimal relation between the difference in level and the necessary minimum length of the slope is given as:

Length $=\{$ (height $-0,1) \times 11,1+10\} \times$ height $\quad$ (with length and height in terms of meters) (Fig. 4).

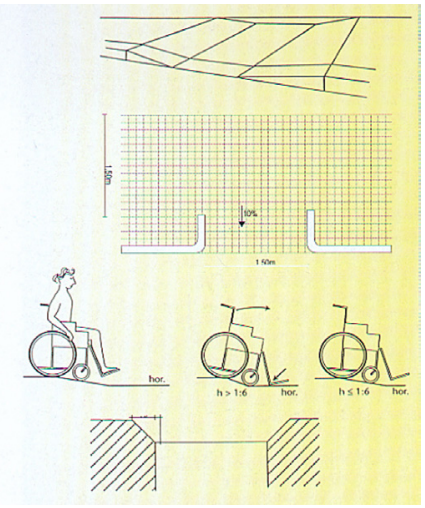

Figure 3.

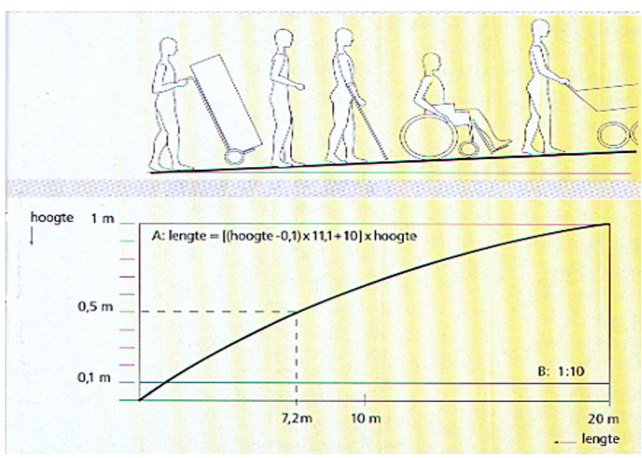

Figure 4.

\subsection{Orientation and measures for blind people and people with restricted visibility}

- designers must create or repair as much as possible the natural guide-lines to assure the orientation and must be attentive with artificial guide-lines which are sometimes necessary because of a lack of these can be dangerous for visual handicapped people due to total disorientation (Fig. 5)

- rattle systems are preferable for comparing e.g. crossing points with traffic lights. The green phase must be calculated with a walking speed of a maximum of $0,5 \mathrm{~m} / \mathrm{sec}$ at the start of the green phase (Fig. 6)

- warning markings are only desirable and advisable at dangerous crossing points for visual handicapped people. The designer must be logical and economical when using warning constructions at crossing points e.g. there should be no warning constructions at traffic lights with rattles in service during the night, no warning constructions if there are no zebra crossings in zone 30 areas, on an elevated continuous pedestrian path, or in residential areas with restrictions to slow down traffic (residential street)

- warning markings exist of squared bump paving which is placed in a perpendicular pattern in the walking direction (Fig. 7)

- colour contrasts are advisable to mark transparent or glass walls

- rubber pavings are information markings (Fig. 8) 
- steps going down in garages, parking areas, or underground are very dangerous for visually handicapped people. These dangerous areas must be marked with a uniform warning system

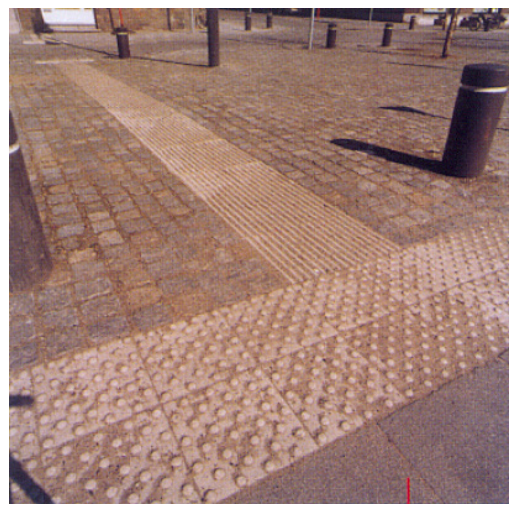

Figure 5.

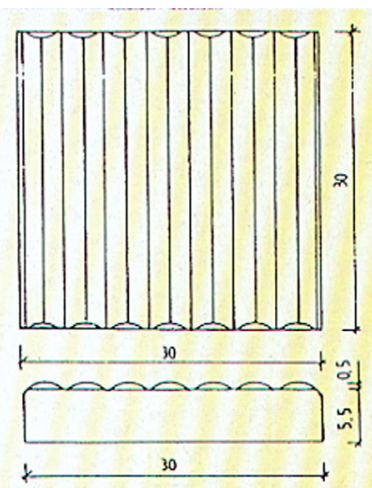

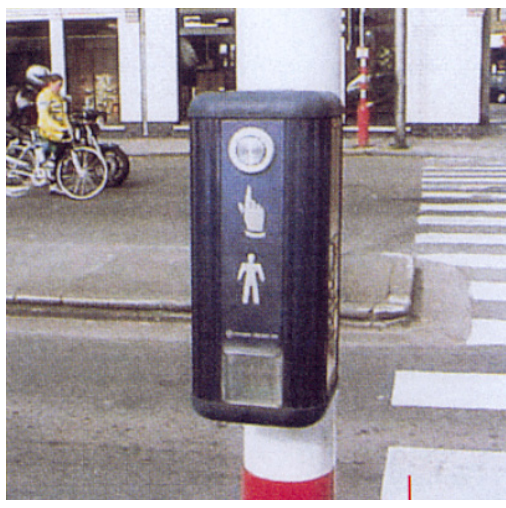

Figure 6.

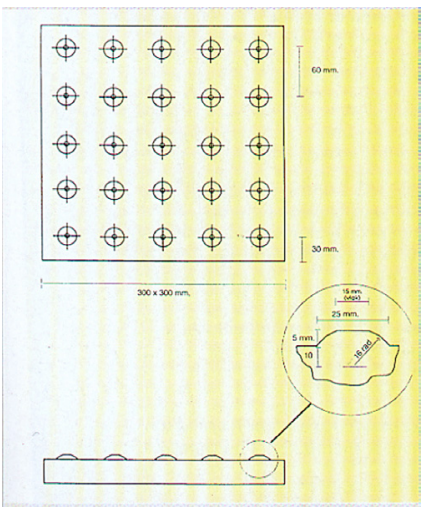

Figure 7.
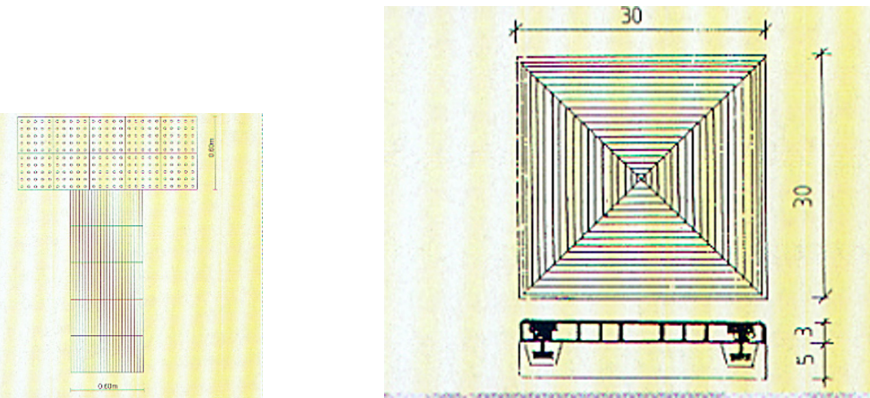

Figure 8. 
- fences as warning measures are necessary to indicate construction sites on the walking area, e.g. construction sites and sites of cable companies

- information and service: the placement of operation elements must take into account tall persons, small persons and wheelchair users. Operation elements used for rattles, phones, etc. must be useable by everybody - this means at a correct height, with correct readable information, which is reachable and located in a logical way.

\section{Practical cases}

\subsection{Pedestrians}

1. A comfortable walking area is passable, with sufficient movable space and is obstacle free (Fig. 9)
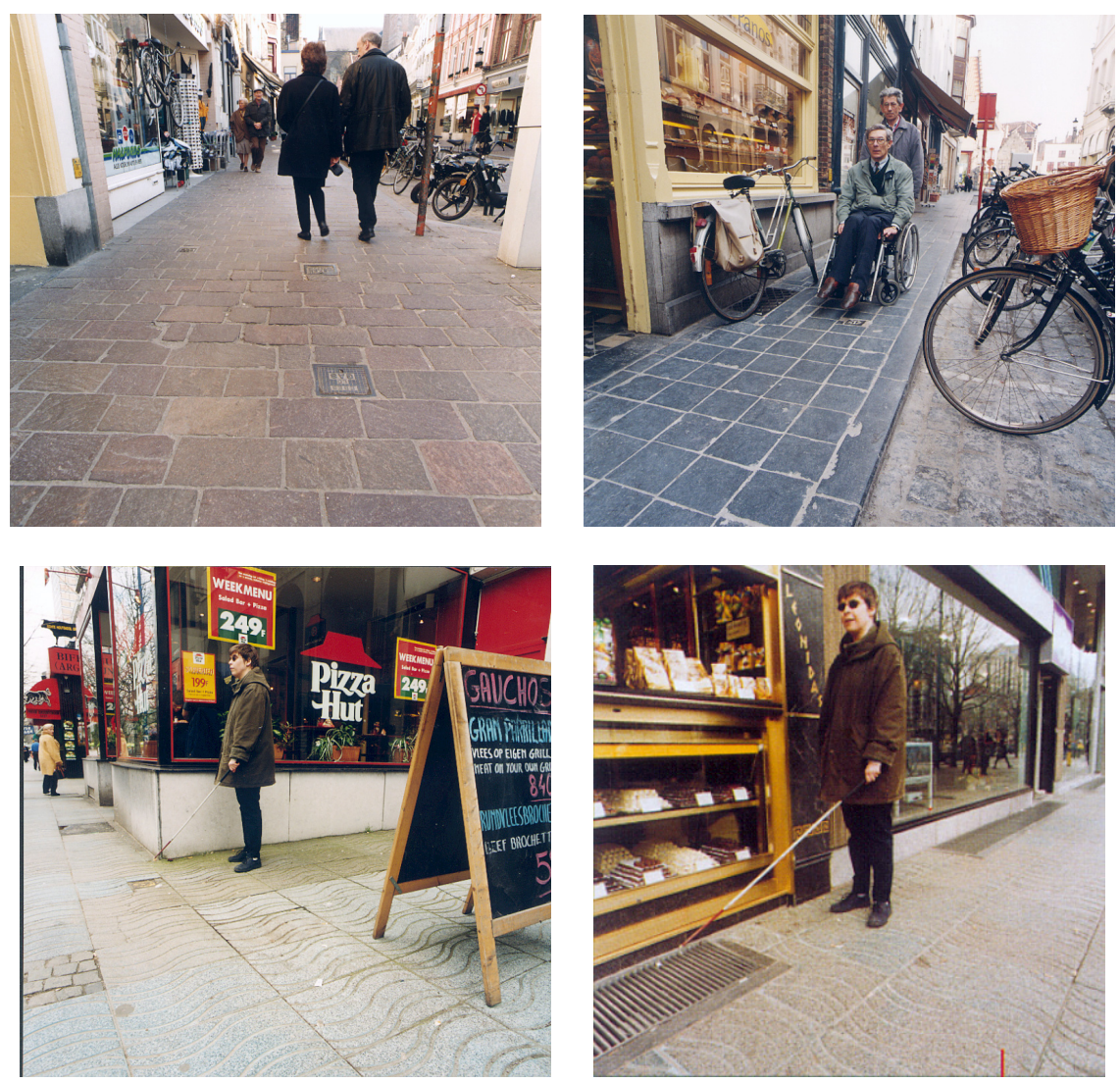

Figure 9. 
2. Safe and comfortable crossings (Fig. 10)
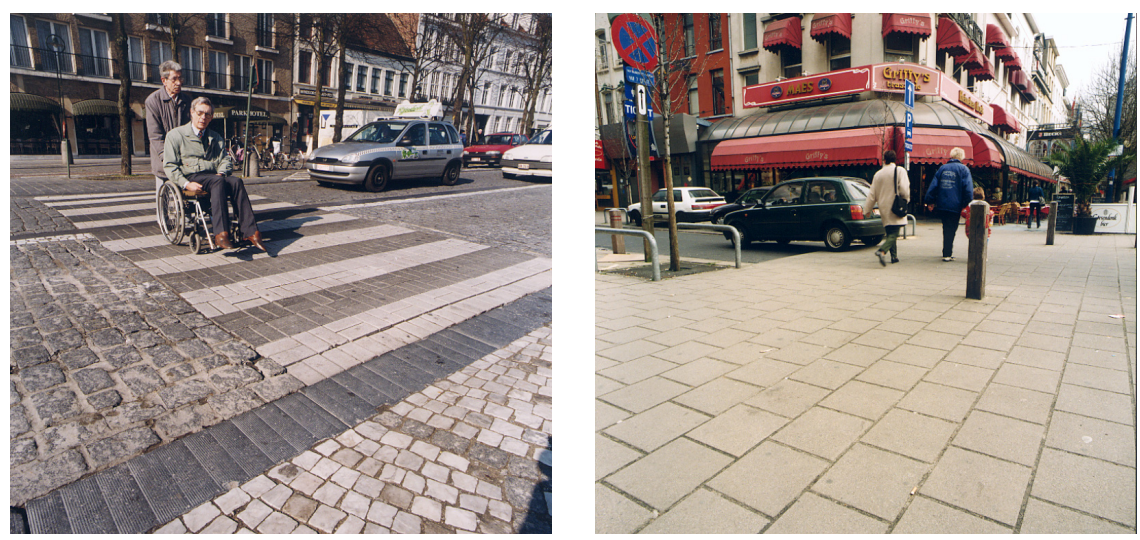

Figure 10 .

- guarantee low speed combined with a ground level construction

- the difference in level between road and pedestrian path can be eliminated by increasing the height of the crossing point or a part of the road

- the pedestrian path can be elevated on the side roads

- differences in levels must be linked in a comfortable way (Fig. 11)

- the crossing distance must be restricted and a low contact speed between pedestrians and drivers guaranteed

- safe measures must be taken on crossing points with dense traffic
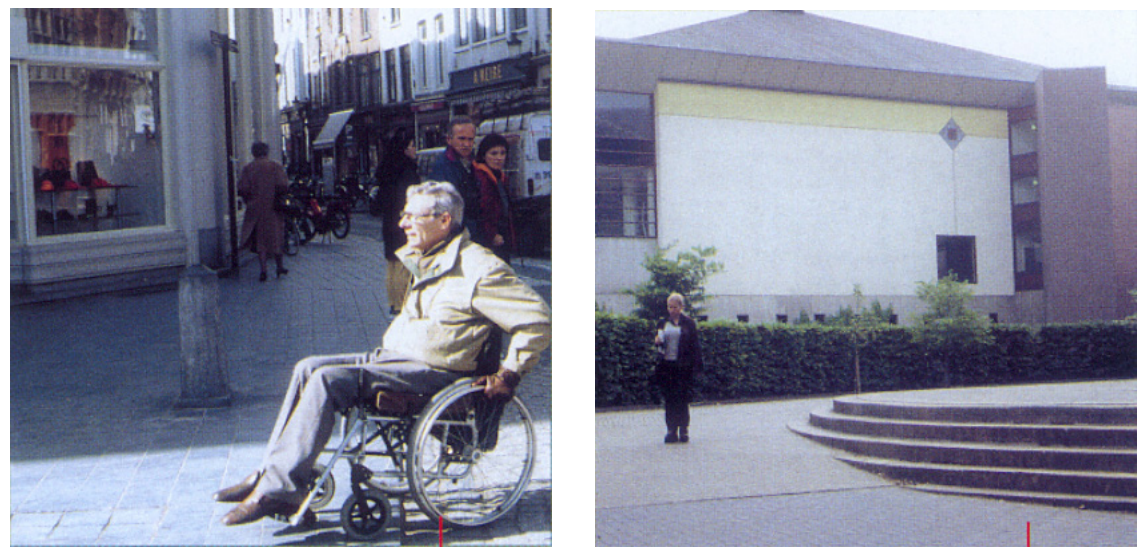

Figure 11. 


\subsection{From pedestrian to car driver or car passenger}

1. Number of parking places: the number of accessible parking places for handicapped people is a minimum $4 \%$ of the total number of parking places (Fig. 12)

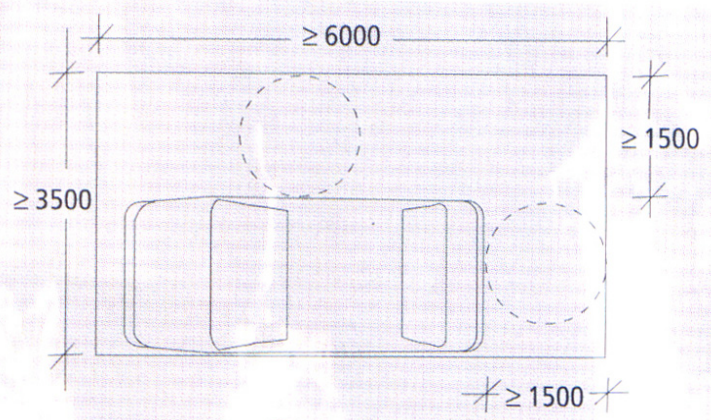

Figure 12.

2. location of the parking places:

- parking places for handicapped people must always be located at the end of the parking areas in order to guarantee accessibility.

- $\quad$ parking places in buildings for handicapped people are located as near as possible to the entrance of the building. A parking place in a parking garage is located as near as possible to the elevator or the pedestrian exit.

- directives: the free space around the vehicle to allow moving in/out the vehicle must be more than $1,50 \mathrm{~m}$.
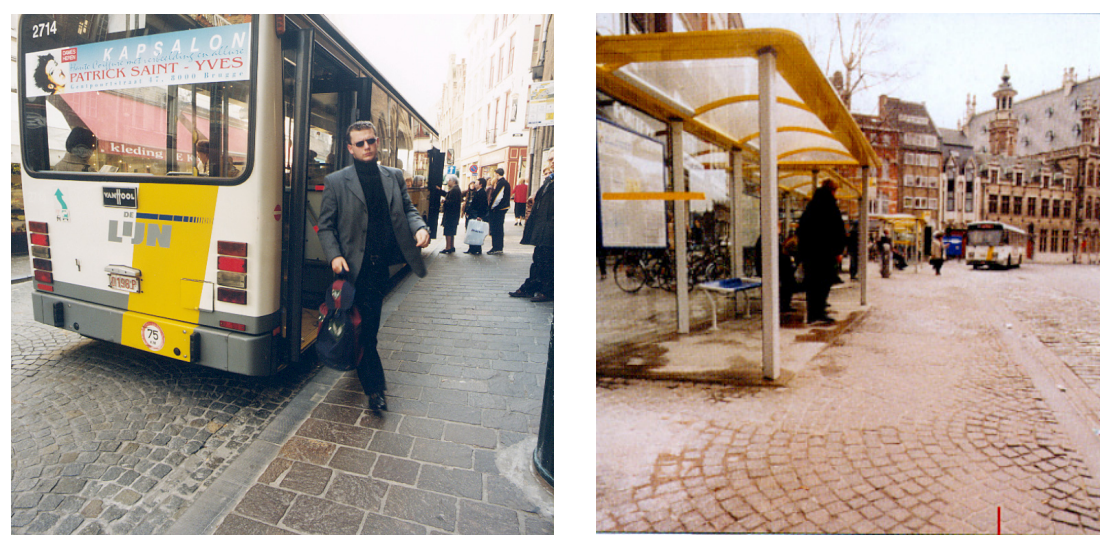

Figure 13. 


\subsection{From pedestrian to user of public transport (Fig. 13)}

1. accessible low platform entries in buses

2. accessible and comfortable waiting areas with ground level access to hiding places with dimensions 3,00 x 1,50 m (type A) ; 4,00 x 1,50 m (type B) or $4,80 \times 1,80 \mathrm{~m}$ (type $\mathrm{C}$ ), incl. exact slope and maximum difference in level of $2 \mathrm{~cm}$ and seating with a seat level of $45-50 \mathrm{~cm}$.

3. comfortable entrance/exit with minimum distance between vehicle and platform or stop place, and good accessible and logical located hiding places and sufficient and clear information.

\section{Suggestions for management and maintenance of the public area}

a. Regular maintenance of the walking area

b. Efficient use of the walking area

c. Special measures to take into account construction sites.

\section{References}

[1] Naar een Integraal Toegankelijk openbaar domein, Ministerie van de Vlaamse gemeenschap 1999.Toegankelijkheidsbrochure, Belgische Confederatie van blinden en slechtzienden vzw Brussel 1999.

[3] Ministerieel besluit van 7.5.1999 betreffende het signaleren van werken en verkeersbelemmeringen op de openbare weg.

[4] De waarneming van geleidelijnen en markeringen, Kooi. F.I., Walraven J., Nederlandse organisatie voor toegepast natuurwetenschappelijk onderzoek TNO, Soesterberg 1998.

[5] Algemene bouwverordening inzake wegen voor voetgangersverkeer Belgisch Staatsblad 1997.

[6] Handboek voor toegankelijkheid, Wijk Maarten, Misset, Doetinchem 1997. 